\title{
Analysis of environmental factors about cerebral stroke
}

\author{
Wenbin Liu
}

Department of Basics, Wuhan Yangtze Business University, Wuhan, China; cq2200@126.com

Received 14 October 2013; revised 16 November 2013; accepted 27 November 2013

Copyright (C) 2013 Wenbin Liu. This is an open access article distributed under the Creative Commons Attribution License, which permits unrestricted use, distribution, and reproduction in any medium, provided the original work is properly cited.

\begin{abstract}
In this paper, the disease of cerebral stroke is studied mainly. According to the basic information of the patient, Linear fitting method is applied to calculate between the number of sick and age by using MATLAB software. According to data of pressure, temperature and humidity, nondimensionalizing by normalization method, linear regressions are analysed between the number of the patient and pressure, temperature, humidity. According to the important feature and the key indicators of cerebral stroke, high-risk groups are proposed to the early warning and intervene.
\end{abstract}

Keywords: Cerebral Stroke; Environmental Factors; Regression Analysis; The Incidence

\section{INTRODUCTION}

Cerebral stroke is one of important diseases which harm to human health in today's world. Cerebral stroke is a scientific name of cerebral apoplexy. It is circular and disordered disease of cerebral blood that makes people fall ill suddenly. It is called cerebrovascular accident also. The patient of cerebrovascular disease gives rise to the obstacles of acute cerebral blood circulation, because some inducing factors that lead to cerebral artery are stenosis, occlusion or rupture. It represents clinical symptom and sign of brain disorder transiently or perpetually. Cerebral stroke is divided into cerebral arterial thrombosis and hemorrhagic apoplexy.

Cerebral stroke is one of the serious diseases threatening human life now. It was a long process that one person has the disease (cerebral stroke), but it is very difficult to reverse. It has been shown that there is a close relationship between cerebral stroke and environmental factors including air temperature and humidity. Analysing [1] environmental factors of cerebral stroke, its purpose is to assess the risk of disease. The high risk population of stroke can take timely intervention. Healthy people who have not been sick or subhealth people are aware of their degree of risk of stroke, thus protecting themselves. At the same time, establishing data model, and mastering the disease incidence rule, it is of practical guiding significance that the administrative department of public health and medical institutions reasonably allocate medical power, improve the medical treatment environment, and allocate beds and medical drugs [2].

\section{MATERIALS}

In the paper, the data come from Southwestern Guizhou Province Health Bureau in China about the case of cerebral stroke from January 2007 to December 2010 and daily meteorological data of the local including air temperature, air pressure and relative humidity in the corresponding period [3].

\section{THE NUMBER OF SICK AND AGE}

\subsection{Method}

As the object of study in an area about cerebral stroke, its purpose is that the risk of disease is assessed, high risk population of cerebral stroke can be adopted timely as intervention measures, and sub health people acquaintances his own degree of risk about cerebral stroke and preserves himself. At the same time, by means of data model being set up, scientific basis is provided as controlling disease.

Subtotal is in Table 1 about the number of sick of all ages.

Linear fitting method is applied to calculate between

Table 1. The number of sick of all ages.

\begin{tabular}{ccccccc}
\hline Age & $0-20$ & $21-40$ & $41-60$ & $61-80$ & $81-100$ & More than 100 \\
\hline $\begin{array}{c}\text { The number } \\
\text { of sick }\end{array}$ & 48 & 611 & 8255 & 29,332 & 12,108 & 11 \\
\hline
\end{tabular}


the number of sick and age by using MATLAB software.

\subsection{Result}

The function is obtained as follows:

$$
y= \begin{cases}1.7426 x-9.1003 & (0<x \leq 40) \\ 0.059 x-2.467 & (40<x \leq 70) \\ -0.0199 x+2.7082 & (70<x \leq 84) \\ -0.0144 x+1.4642 & (84<x \leq 120)\end{cases}
$$

( $y$ represents the number of sick, and $x$ represents age.)

\subsection{Discussion}

From the function expression, we may obtained that the incidence rate is very low from 0 to 40 years old, the incidence rate from 50 to 70 years old is more 20 times than the incidence rate of below 50 years old, and the incidence rate reduces after over 70 years old. Because the people from 0 to 40 years old have strong resistance, the incidence rate is very low. With the growth of age, the degree of arterial stiffness is increased, and the incidence rate of cerebral stroke obviously increase. But cardinal number of the old population is small, it results that the number of sick rapidly reduce.

\section{THE INCIDENCE OF CEREBRAL STROKE AND ENVIRONMENT}

\subsection{Method}

The incidence of cerebral stroke is analysed from environment. We know that the incidence of cerebral stroke is more or less affected by temperature, pressure and humidity from the data. The relation between the incidence of cerebral stroke and temperature, pressure or humidity is described by using multiple linear regression. Firstly, we obtained data between the number of patients and temperature, pressure or humidity from statistical data in Table 2:

Thus the data are dealt within dimensionless form. We use the following formula (range normalization method):

$$
k_{i}^{\prime}=\left(k_{i}-k_{\min }\right) /\left(k_{\max }-k_{\min }\right)
$$

We find out the maximum and minimum values of temperature, pressure or humidity by using excel software. They are substituted into the above formula. We obtain the following formula:

Relative average temperature:

$$
x_{1}^{\prime}=\left[x_{1}-(-7.1)\right] /[39-(-7.1)]
$$

Relative average humidity: $x_{2}^{\prime}=\left(x_{2}-0\right) /(97-0)$

Relative average pressure:

$$
x_{3}^{\prime}=\left(x_{3}-992.2\right) /(1040.4-992.2)
$$

We obtain the data in Table 3:

Thus the relation between the number of patients and relative temperature, pressure or humidity may be analysed by using spss software.

\subsection{Result of the Number of Patients and Relative Average Temperature}

By using spss software, the relation between the number of patients and relative average temperature can be displayed by the following fitting function: $y=43.059-1.751 x_{1}$.

Table 2. The number of patients and temperature, pressure or humidity.

\begin{tabular}{ccccc}
\hline Date & $\begin{array}{c}\text { The number } \\
\text { of patients }\end{array}$ & $\begin{array}{c}\text { Average } \\
\text { pressure }\end{array}$ & $\begin{array}{c}\text { Average } \\
\text { temperature }\end{array}$ & $\begin{array}{c}\text { Average } \\
\text { humidity }\end{array}$ \\
\hline $2007-1-1$ & 91 & 1025.1 & 8.1 & 86 \\
$2007-1-2$ & 32 & 1025.2 & 6.5 & 84 \\
$2007-1-3$ & 24 & 1026.1 & 5 & 86 \\
$2007-1-4$ & 36 & 1027.1 & 5.9 & 82 \\
$2007-1-5$ & 33 & 1027.1 & 5 & 84 \\
$\ldots$ & $\ldots$ & $\ldots$ & $\ldots$ & $\ldots$ \\
$2010-12-27$ & 13 & 1017.1 & 5.8 & 58 \\
$2010-12-28$ & 9 & 1018.3 & 6.4 & 45 \\
$2010-12-29$ & 8 & 1020.9 & 6.1 & 58 \\
$2010-12-30$ & 6 & 1023.3 & 2.7 & 29 \\
$2010-12-31$ & 4 & 1025.9 & -1.1 & 28 \\
\hline
\end{tabular}

Table 3. The number of patients and relative temperature, pressure or humidity.

\begin{tabular}{ccccc}
\hline Date & $\begin{array}{c}\text { The number } \\
\text { of patients }\end{array}$ & $\begin{array}{c}\text { Relative } \\
\text { average } \\
\text { temperature }\end{array}$ & $\begin{array}{c}\text { Relative } \\
\text { average } \\
\text { pressure }\end{array}$ & $\begin{array}{c}\text { Relative } \\
\text { average } \\
\text { humidity }\end{array}$ \\
\hline $2007-1-1$ & 91 & 0.330 & 0.683 & 0.887 \\
$2007-1-2$ & 32 & 0.295 & 0.685 & 0.866 \\
$2007-1-3$ & 24 & 0.262 & 0.703 & 0.887 \\
$2007-1-4$ & 36 & 0.282 & 0.724 & 0.845 \\
$2007-1-5$ & 33 & 0.262 & 0.724 & 0.866 \\
$\ldots$ & $\ldots$ & $\ldots$ & $\ldots$ & $\ldots$ \\
$2010-12-27$ & 13 & 0.280 & 0.517 & 0.598 \\
$2010-12-28$ & 9 & 0.293 & 0.541 & 0.464 \\
$2010-12-29$ & 8 & 0.286 & 0.595 & 0.598 \\
$2010-12-30$ & 6 & 0.213 & 0.645 & 0.299 \\
$2010-12-31$ & 4 & 0.130 & 0.699 & 0.289 \\
\hline
\end{tabular}




\subsection{Discussion of the Number of Patients and Relative Average Temperature}

It is explained that there is a negative correlation between the number of patients and relative average temperature. Because when the temperature falls, the human body sweat will be less than before so that blood volume is increased. When the weather is cold, the human body dissipates the heat fast. In order to maintain body temperature, the sympathetic nervous is excited. Further, blood pressure is elevated. Cerebral stroke is easy to occur.

\subsection{Result of the Number of Patients and Relative Average Humidity}

By using spss software, the relation between the number of patients and relative average humidity is in the following fitting function: $y=50.193-11.015 x_{2}$.

\subsection{Discussion of the Number of Patients and Relative Average Humidity}

It is explained that there is a negative correlation between the number of patients and relative average humidity.

\subsection{Result of the Number of Patients and Relative Average Pressure}

By using spss software, the relation between the number of patients and relative average pressure is in the following fitting function: $y=41.205-1.947 x_{3}$.

\subsection{Discussion of the Number of Patients and Relative Average Pressure}

It is explained that there is a negative correlation between the number of patients and relative average pressure.

\subsection{Result of the Number of Patients, Relative Average Temperature, Pressure and Humidity}

There is a linear relation between the number of patients and relative average temperature, pressure or humidity respectively, thus the linear relation between the number of patients, relative average temperature, pressure and humidity may be analyzed with multiple linear regressions. By using spss software, the relation between the number of patients, relative average temperature, pressure and humidity is in the following fitting function: $y=51.995-1.732 x_{1}-11.127 x_{2}-1.694 x_{3}$. There, $y$ represents the number of patients, $x_{1}$ represents relative average pressure, $x_{2}$ represents relative average temperature, and $x_{3}$ represents relative average humidity.

\subsection{Discussion of the Number of Patients, Relative Average Temperature, Pressure and Humidity}

In conclusion, there is a negative correlation between the number of patients, relative average temperature, pressure and humidity. It indicates that the incidence of cerebral stroke is high as the low temperature, the low pressure and the low humidity. The incidence of cerebral stroke is highest in the cold winter. The incidence of cerebral stroke began to fall when the weather is warm in the spring. The incidence of cerebral stroke is lowest in the hot summer. The incidence of cerebral stroke began to rise in the autumn. In a cold environment, peripheral vascular of human body contracts, peripheral resistance is increased, and blood pressure is elevated. In a cold environment, the fibrin in blood is increased, blood viscosity is usually elevated, therefore, thrombus is easy to form. Especially in the sleep state, blood flow is slow. If the temperature of the room is low, cerebral thrombosis is easy to occur. When the temperature is suddenly changed, these physiological reactions perform easily, and blood pressure fluctuates obviously. Cerebral stroke is easy to occur between the old people and the risk factor of cerebral stroke. Therefore, we should pay attention to weather changes, and keep warm constantly [4].

\section{REFERENCES}

[1] Yang, H.P. and Shi, P. (2002) The relationship between stroke and meteorological factors. Journal of Zhangjiakou Medical College, 19, 47-48.

[2] Yu, L.M. (2008) Analysis of risk factors of stroke and nursing intervention. Journal of Chengde Medical College, 25, 53.

[3] Information on http://www.mcm.edu.cn/problem/2012/2012.html

[4] Zhu, M., Yan, F.Y. and Ji, H. (2008) Analysis of the risk factors in recurrent stroke and nursing countermeasures. The Theory and Practice of Rehabilitation in China, 14, 799-800. 